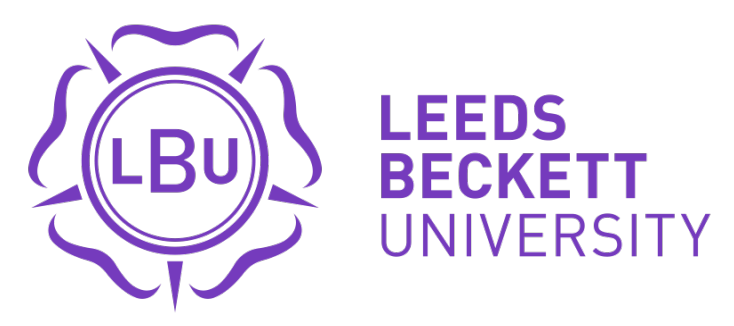

Citation:

Bridge, G and Fawkes, J and Tench, R (2021) Between a rock and a hard place: publishing issues in public relations and communication management. Journal of Communication Management. ISSN 1363-254X DOI: https://doi.org/10.1108/jcom-11-2020-0152

Link to Leeds Beckett Repository record:

https://eprints.leedsbeckett.ac.uk/id/eprint/7879/

Document Version:

Article (Accepted Version)

Creative Commons: Attribution-Noncommercial 4.0

The aim of the Leeds Beckett Repository is to provide open access to our research, as required by funder policies and permitted by publishers and copyright law.

The Leeds Beckett repository holds a wide range of publications, each of which has been checked for copyright and the relevant embargo period has been applied by the Research Services team.

We operate on a standard take-down policy. If you are the author or publisher of an output and you would like it removed from the repository, please contact us and we will investigate on a case-by-case basis.

Each thesis in the repository has been cleared where necessary by the author for third party copyright. If you would like a thesis to be removed from the repository or believe there is an issue with copyright, please contact us on openaccess@leedsbeckett.ac.uk and we will investigate on a case-by-case basis. 


\title{
Between a rock and a hard place: Publishing issues in public relations and communication management
}

\begin{abstract}
Purpose: Exploration of the pressures to publish facing European public relations (PR) and communication management scholars across career stages.

Design/ methodology/ approach: The Delphi method was employed with public relations and communication management scholars at associate professor level or higher across Europe. An online survey was then shared with the wider academic community to gather insights from scholars at different career stages.

Findings: The suitability and status of the journal and the language of the outputs are considered. Academics are caught between the rock of publishing inside the field to support its development and the hard place of being required to publish in high ranking journals for funding and promotion. Scholars are evaluated regularly, with journal articles being the main unit of assessment. Academics, regardless of career stage, feel under pressure to publish.

Limitations: The wider survey enabled publishing insights to be gathered from academics across the career spectrum, but it was completed by a small sample. Nevertheless, similar concerns emerged from both methods of data gathering, suggesting a clear agenda for discussion and further research.

Practical implications: Public relations and communications management is an academic discipline without an accepted list of high impact journals. This study provides an annotated journal list to aid institutional evaluations, aid scholarly journal publishing decisions and support early career researchers navigating the publishing process.

Value: Adds to the somewhat limited discussion regarding how academics in public relations and communication management decide where to publish and provides a resource that can be used by scholars, institutions and funders.
\end{abstract}

Keywords: Communication management; Public relations; Strategic communications; Publishing; Evaluation and ranking; Early career researchers; Journals 


\section{Between a rock and a hard place: Publishing issues in public relations and communication management}

\section{Introduction}

Public relations (PR) as a practice can be traced back to ancient times, but it began to take shape as a profession through the formation of professional associations and university-level education after the Second World War, when the education of public relations practitioners was considered vital (Tench and Yeomans, 2013; L'Etang, 2004). Since the 1960s, public relations and communication management has been taught widely as an academic discipline in the US, with European education expanding in the 1990s. Today, degree-level entry is standard in the field. For instance, a recent census report from the UK revealed that $80 \%$ of public relations and communications management professionals have an undergraduate degree in any subject (PRCA, 2019, p. 12).

During the 1990s, the model shifted from vocational 'training' to higher education, incorporating theoretical debates, to meet degree requirements and to develop higher-order reflective skills. Watson's (2015) seventy country study explores factors that aided the expansion of the practice and the restraints that slowed growth at this point in its evolution. At the same time, academic staff came under increased pressure to be research active and to publish in respected journals. This was part of a movement for greater accountability from universities to the taxpayer and other research funding bodies. To assess research outputs and their impacts, a series of measures and evaluation systems were introduced (Bence and Oppenheim, 2005). These vary across Europe and are yet to be introduced in some countries. However, they commonly comprise evaluation of academic research taking place in universities and university colleges through submission of selective work demonstrating standards of research in given fields, assessed and graded through a system of peer-reviewing 
panels. In some European countries, such as the UK, the evaluation systems include the requirement to demonstrate the breadth of research activity across faculty and the impact of research on wider society (REF, 2020). One of the key elements in this process is the publication record of faculty, within many places, a sliding scale of expectations, depending on the academic's position in the career trajectory. There is a strong premium in publishing in highly regarded journals, particularly those which feature in existing lists of recommended or ranked publications, such as the Australian Business Deans Council (ABDC).

Public relations and communication management is considered a mature field in terms of publishing history and theoretical development (Eyun-Jung, Pasadesos and Ertem-Eray, 2019). Nevertheless, there is a limited number of journals in the field, which offers a limited amount ef restricts publication opportunities, especially in high-quality international journals. English language publications are also often the only journals with recognition in ranking systems and even there they do not score highly. For example, Public Relations Review, which at present is the highest-ranking journal in the field of public relations, ranked as an 'A' journal in the ABDC Marketing Journals List, has a journal impact factor (JIF) of just 1.616 and a CiteScore of 2.34 (Mutum, 2019). This is compared to marketing specific journals such as Industrial Marketing Management which has a JIF of 4.695 and a CiteScore of 9.1 (Elsevier, 2020). Therefore, any academic in the field of public relations will be aware that their best prospect for publication carries less weight in evaluation systems than their colleagues in many other disciplines. Other fields of study that lack preferred journal lists, such as tourism, also struggle with this issue (Tung and McKercher, 2017).

Given these challenges, the purpose of this paper is twofold. First, we solicit the perceptions and experiences of public relations and communication management scholars regarding how they decide where to submit manuscripts. Second, we explore whether publishing decisions 
and the factors that impact them vary at different career stages or in different contexts. Our study adds to the current knowledge base by providing a deeper understanding of publishing practices from the scholarly level perspective. This is central to understanding what factors might drive or hamper publishing in the field, and therefore important to consider for performance evaluation and career progression of scholars.

\section{Literature review}

\section{University research performance indicators}

Due to growing pressures for evaluation and auditing of public spending in the UK, in the 1980s assessments of academic research were conducted to ensure it met the 'three e's: economy, efficiency and effectiveness' (Rhodes, 1994). Indicators to measure scientific output and scientific impact were developed (Burke et al., 1983). Such assessments were also used by institutions to manage and develop research strategies and to assess research quality for interuniversity competition for staff, students and resources. In the 1990s assessments were expanded to include the wider impacts of research. However, despite the rise of such alternative metrics, otherwise called third stream activities (Salter et al., 2002), public values (Bozeman and Sarewitz, 2011) or societal relevance (Holbrook and Frodeman, 2010), which could support the transition to a more open, accountable and outward-facing research system, journat impact factors (JIFs) remain the most widely used bibliometric indicator for academic assessment.

The Research Excellence Framework (REF) is the latest assessment system employed in the UK to enable the British government to audit and monitor the research output of UK universities (CareersAdvice, 2011; REF, 2020). It considers factors beyond JIF and is employed 'to support the desire of modern research policy for promoting problem-solving research'. The REF has been cited as being one of the most thorough impact assessments in 
the world. Despite conceptual and methodological problems, discussed below, it still emphasizes publishing in journals of international repute, which means it is important for academics to know how journals are ranked in their field. Many other PRFS, that employ similar methods to the UK REF, have been implemented across Europe to evaluate academic outputs. However, PRFS have been widely criticized since none has been developed to fully capture the diversity of academic impact. For instance, the use of PRFS in research assessment is 'dominating minds, distorting behavior and determining careers' (Lawrence, 2007), placing unnecessary stress and pressure on academics and leading to the abandonment of certain types of work (e.g. teaching, outreach) (Wouters et al., 2015).

\section{Journal ranking systems and the pressure to publish}

JIFs are frequently used as the primary parameter with which to compare the scientific output of individuals and institutions. However, JIFs were created as a tool to help librarians identify journals to purchase, not as a measure of the scientific quality of research, and thus they have limitations which include: highly skewed citation distributions within journals (Adler et al., 2009; Seglen, 1997); field-specific and calculated across multiple, highly diverse article types (Vanclay, 2012); can be manipulated by editorial policy (PLoS Medical Editors, 2006); and the data used to calculate the JIFs are not transparent or openly available to the public (Rossner et al., 2007; Vanclay, 2012).

Due to the challenges of JIFs, it has been argued that new policies and practices should be developed to change the research assessment process to improve equity. For instance, a group of organizations and individuals have signed a Declaration on Research Assessment (DORA), which calls for the 'use of new tools and processes in research assessment and the responsible use of metrics that align with core academic values and promote consistency and transparency in decision-making' (DORA, 2019). Despite these calls, research assessment continues. These 
assessments place pressure on scholars and institutions. As Honig et al. (2014) stated, writing about management scholarship, business schools worldwide are under pressure to value only research published in top ranked journals, which in turn pressurizes scholars to adopt an "an entrepreneurial perspective, driving them to consider the risk/return profile of the work they may wish to undertake" (p. 124). This involves calculating how to maximize high value publication output to secure tenure or promotion, rather than deepening understanding of their subject.

The 'performance' of academic excellence is explored in Oravec (2017) who gives examples of manipulation, such as mutual citations, to increase rating in individual academic indices like Google Scholar. She calls this 'gaming the system" (p 424) and argues it has a higher impact on fields which are unable to meet performative metrics due to limited publication opportunities or journal rankings. The field of public relations falls into this category and is explored below.

\section{Public relations and emerging fields of research}

Public relations scholarship is usually assessed either as a management discipline or as an aspect of communication and media. This reflects issues with field definition that have either limited its development or have encouraged transdisciplinary research (Edwards 2012; Fawkes, 2018). There have been various attempts at mapping public relations scholarship including Trujillo and Toth (1987) who organize research into functionalist, interpretivist and critical paradigms and Edwards (2012) who suggests that rather than create more, antagonistic, boxes we should treat the research approaches and their objects of study as constituting a spectrum. In line with this, Morehouse and Saffer (2018) highlighted the concept of 'invisible colleges' whereby scholars collaborate when publishing and suggest that having a limited number of 
journal outlets could foster this. A further, recent overview of the public relations landscape is also offered by Moloney and McGrath (2020).

The pattern of publishing in public relations is explored by Eyun-Jung, Pasadeos and ErtemEray (2019) who repeat earlier bibliometric analyses of articles in leading public relations journals (Ferguson, 1984; Sallot et al, 2003). They find that several key areas have emerged from the aggregated research field over time (namely crisis communication, relationship management, new technologies, and dialogic communication, in addition to the continuing influence of excellence theory). They also note that the pattern of research is indicative of a mature discipline, with most citations referring to recent works and decreasing reliance on textbook sources. They also note the (undocumented) rise of publishing in related fields' journals. Despite this, public relations and communication management lacks a recognized list of quality journals.

There is little academic research into the publishing experience in public relations, the profile of the academic in tourism offered by Tung and McKercher (2017) will be familiar to public relations educators due to the common issues experienced. The researchers outline the progression from practitioners starting professional courses in the $1970 \mathrm{~s}$ and $80 \mathrm{~s}$, through the expansion of the discipline through the 90 s and early 2000s. In the second phase, practitioners acquired doctorates as they moved into education. Newer entrants, they say, have a 'much tougher environment .... with diminishing job opportunities [which] mean that many candidates must hold a doctoral qualification and have an extensive publication record just to qualify for an interview' (p. 322). Moreover, Tung and McKercher (2017) find new and emerging scholars (NES) face pressure to publish in international journals, a challenge for nonnative English speakers. Tung and McKercher also note the effects of these strategies on the 
development of a field, as scholarship tends to fragment and dissipate for academics to 'perform' to target.

\section{Theoretical approach - The Performative University}

The terms performance and performativity are widely used and widely interpreted across a range of academic disciplines, including anthropology, sociology, linguistics and theatre studies (Albu and Flyverbom, 2019). Both terms are used to mean a) the execution of a task or b) role where performance involves presentation of material to an audience (Velten, 2012). Performativity is a neologism coined by Austin (1962) to encapsulate his sense of words as actions, with particular emphasis on context. Its application in linguistics (e.g. Chomsky) has been extended by Judith Butler (1990/2015) to describe gender as a kind of speech act or utterance, designed to reflect or challenge social norms. Butler's work has shaped discussion of gender identity and fluidity for the past thirty years. As Edwards (2018, pp 180 - 195) suggests, her work is also useful in understanding how power structures may be internalised, with reference to marginalised and minority public relations practitioners and how professional public relations can be 'performed', relevant to the performances required of academics (Oravec, 2017).

The increasing metrification of academic research is sometimes seen as an indicator of its performative nature (Wernick, 1991). Cronin (2016) describes the culture of metrics and audit in HE as constituting a 'PR university' (p.400). She describes this as follows:

...' the PR university captures and pushes forward an idea of the university as a market actor and folds PR thinking and PR practices into core university decision-making... These metrics gain institutional and general societal traction because they offer a means of assessing reputational capital as competitive advantage as it is staged in the media' (p406) 
In such contexts, functions are performed against indices to build up 'reputational capital'. This capital is a currency in the neoliberal development of HE, she argues, citing the "the management of visibilities' (Hansen, Christensen and Flyverbom 2015, p. 125). Moreover, the pressure to perform is passed from institution to individual reinforcing a culture of performance. The 'performance' of academic excellence is explored in Oravec (2017) who gives examples of manipulation, such as mutual citations, to increase rating individual academic indices like Google Scholar; and coercive citations, where pressure from editors causes citation inflation in the JIF. Oravec (2017:424) says inducements to 'game the system' may particularly affect some academic fields [which] are somewhat disadvantaged in terms of performative metrics and their use in the production of faculty stars or star journals, given the number of publication venues available to the fields and historical factors involving the number of citations normally associated with journal articles. While the university as an institution may increasingly be performing its role not as educator but as promoter, the academic discipline of public relations itself is affected by Oravec's observation, with limited high-ranking publishing outlets. Cronin (2016) argues that the PR university not only generates a performative framework though the use of metrics, it performs a set of social values to attract students, faculty and funding. Interestingly, she notes (p 404) that these values need not be believed by any of the players in the performance. Claims about research excellence, student pastoral care standards, employability outcomes matter less, she suggests, than the visible investment in reputational capital, like a film which has put all its budget into special effects.

Following consideration of the above literature and the situational context in European universities, we asked the following questions:

\section{$\underline{\text { Research Questions }}$}


RQ1. How do public relations and communications management academics across different career stages in Europe decide where to publish their research?

RQ2. What factors affect publication decisions made by public relations and communication management academics across different career stages in Europe?

\section{Research approach}

\section{Method}

The study involved two phases. The first phase employed the Delphi method to enable an anonymized debate between senior public relations and communication management academics. Existing or previous members of the European Public Relations Education and Research Association (EUPRERA) network, at the associate professor level or higher, were invited to take part via email. The first round of the Delphi was developed with open ended questions that were based on our two research questions. The Delphi panelists were asked to respond to statements and questions based their insights and opinions on relevant journals and ranking systems. The anonymous responses were aggregated and shared with the group. A further two rounds of questions and aggregated statements were conducted, during which the panelists were asked to comment on suggestions made by other (anonymous) panelists. The assimilated results from previous rounds were reviewed until a degree of unanimity was achieved. The Delphi phase took place over 12 weeks and involved 3 rounds. Each round ran for two weeks (15 October to 29 October 2019; 26 November to 9 December 2019; 8 January to 24 January 2020). Between each round, responses were analyzed to achieve greater levels of consensus. The Delphi method was chosen as it ensures anonymity; there is no need for face to face meetings; freedom from dominant personalities and social pressure; ability to participate irrespective of geography or time constraints; iteration with controlled feedback leading to reflective responses; and statistically measurable group findings (Sourani and Sohail, 2015; Cosic, Shanks and Maynard, 2015). The Delphi method has been used in public relations 
to discover definitions of public relations in Europe (Verčič, et al, 2012); to establish an agenda for public relations research (Wakefield and Watson, 2014; Watson, 2008), and to generate a global capability framework for the field (Gregory and Fawkes, 2019) so is familiar to scholars and practitioners in the field.

The second stage of the study was a wider consultation using an online survey methodology. The outcomes of the Delphi informed the development of the wider survey to understand the publication experiences of scholars at different stages in the academic career path within the field of public relations and communication management. Ahead of launching the wider survey, a pre-test survey was run with a sample of respondents. The aim of the pre-test to assess whether respondents would understand the instructions and whether the meaning of questions was clear. Those who undertook the pre-test survey were not eligible to take part in the survey itself. The pre-tests also ensured that the closed questions included enough response categories, and whether any questions might be systematically missed by respondents. Minor changes were made, namely ensuring that questions needing multiple responses could be answered and that brief descriptions of key words were provided in the section headers.

The final survey included open ended and closed questions. In light of the unexpected global lockdowns that occurred due to COVID-19 at the start of the survey, we ran the survey for 6 weeks (16 March to 30 April 2020) to try and get as many responses as possible. A threepronged sampling approach was employed. Convenience sampling via social media platforms (Twitter, LinkedIn and Facebook) and newsletter networks was conducted to reach individuals who were easiest to recruit. Non-random purposive sampling was also applied to recruit respondents specifically from the public relations and strategic communication academic population. Individuals within each of the research teams existing networks were contacted and invited to take part via email by the research team. Snowball sampling was also conducted to reach a larger population, and to ensure that the sample included a range of academics from 
across the career spectrum. Once an individual had completed the survey, he or she was also invited to recommend others in their network to be surveyed.

\section{$\underline{\text { Sample }}$}

For the Delphi phase, 26 experienced public relations and communications management academics from across Europe were invited to take part in the first round of the Delphi. Fifteen panelists agreed to take part ( 6 females, 8 males). All panelists were invited to take part in the second round, of those, twelve took part ( 5 females, 7 males). The same twelve were invited to take part in round three, and all panelists agreed to take part.

For the wider survey, purposive sampling via email, convenience sampling via social media, and snowball sampling were used. Whilst the number of public relations academics in Europe is not known, the figure is likely to be in the hundreds rather than thousands. Eighty-six participants completed the wider survey. We ensured that none of the Delphi participants also took part in the survey. Fifty responses were removed because they were less than 80 percent complete and had been completed in less than 2 minutes. Six were removed because the respondent did not actively publish or did not work in Europe. The final sample consisted of 31 respondents, which although small, and does not allow us to infer statistical significance insights gained from the survey enhance the Delphi findings and merit further investigation. In the final sample, 14 (46.6 pereent) female, 16 (53.3 pereent) male. Most respondents ( $\mathrm{n}=29$; 96.6 pereent) defined themselves as white. One respondent defined themselves as mixed or multi-ethnic. Most respondents reported to have worked 'in the field' $(\mathrm{n}=25,83.3$ percent), with roles including consultants, teachers, head of departments and managers. A range of career stages were included in the survey, but most were mid-career $(>5$ years tenured academic experience) $(\mathrm{n}=7,23.3$ pereent) or late career (professor or similar) $(\mathrm{n}=14,46.6$ pereent). Of the remaining respondents, 5 (16.6 percent) were doctoral researchers, 2 ( 6.6 percent) were 
early career researchers (ECRs) and 2 were early tenure $(<5$ years tenured academic experience). The respondents represented a sample of academics from institutions across Europe, with 13 from Northern Europe and Scandinavia (Austria/ England/ Finland/ Ireland/ Netherlands/ Switzerland/ UK/ Germany), and 14 from Southern and Eastern Europe (Bulgaria/ Italy/ Portugal/ Spain/ Turkey).

\section{$\underline{\text { Measures }}$}

The questions included in the first round of the Delphi phase were open ended to allow respondents to state their perceptions freely. To assess publication outlets, panelists were asked to provide their 5 most frequently selected journals. To explore the factors affecting publishing decisions, panelists were asked 'what criteria do you use to determine where to submit articles' and 'does your employer/ academic body make suggestions as to desirable journals?'. As language was identified as a factor affecting publishing success in the literature review, panelists were asked to state if language is a factor when selecting journals to publish in. Panelists were also asked whether they had experienced any challenges when publishing, and if so, to state them. As the Delphi rounds progressed, the responses to the questions were assimilated to achieve greater levels of consensus. In the second and third rounds of the Delphi, a mix of open ended and Likert-style questions were used.

In the wider survey, publishing experiences were explored using multiple choice and free text questions. By asking 'Please list the most frequent places where you publish, including academic journals or practical outputs' we explored where academics published. Respondents were asked about how decides on the publication outlet by two questions, 'Who decides where you publish?' [Yourself, supervisor, institution guidelines, collaborators'], 'At what point do you decide where to publish?' [Conception of a study, design stage, data stage, data collection, data analysis, end of writing up]. Building on the preferred journal outlets identified in the 
Delphi phase, we assessed the perceived quality of journal outlets by asking respondents to 'Please move and place these journal titles [Public Relations Review, Journal of Communication Management, Corporate Communications, European Journal of Communication Research, International Journal of Strategic Communication] in order of how likely you would be to choose them as an outlet for publication.' Respondents were also asked if they had published or tried to publish in the same five journals.

Factors affecting publishing decisions were assessed by asking respondents to select factors from a multiple-choice list [JIF, speed of review, peer recommendations, previous experience, special issue calls]. The factors included in this list were identified in the Delphi phase. As language was identified as a challenge for academics seeking to publish in the Delphi phase, experiences were explored in the wider survey. Respondents were asked 'Is English your first language?', and 'Do you need/use support to write in English?' [Translation, editing, proofreading]. Support for publishing in English was assessed 'Does your institution support publication in non-English journals?' and 'Are there any services to help academics with publishing in English?'

The penultimate section of the survey asked respondents about the pressure to publish, and the use of publication metrics and evaluative frameworks by institutions. These questions were assessed via a series of multiple-choice questions. For instance, 'What are your institutions' expectations about journal publishing?' [Publish a set number of high impact outputs every year, senior academics must publish a set number of high impact outputs every year, other]. As pressure to publish was highlighted in the Delphi phase, survey respondents were asked 'Do you feel under pressure to publish?' and 'Are your institutions' expectations about journal publishing the same for all scholars?' The final section sought to explore the nature of publishing in public relations and communication management as an emerging field. 
Respondents were asked if/ how evaluations varied between emerging and more established fields in their institution, and 'have you experienced any challenging in fields outside of public relations and communication management?'

\section{Data analysis}

A combination of open (the respondent composes the reply) and closed (pre-coded response options given) questions were included in the Delphi phase and wider survey. Questions were numbered and grouped by topic. Headings were included to make the questionnaire easier to follow. The demographic data from both phases of the study were analyzed to identify measures of central tendency. In the wider survey, the demographic data was also used to assess if there were differences in terms of age, gender and career stage with publication experiences. Free text questions in both phases were analyzed thematically. All analyses were conducted in Microsoft Excel.

\section{Ethical approval}

Ethical approval was granted by the Leeds Beckett University ethics review board. The respondent's right to confidentiality was respected throughout data collection, analysis and reporting with each respondent given a unique identification number. No personally identifiable information was retained. To ensure informed consent, respondents were asked to read an information sheet and electronically agree to take part in the survey to indicate that they had been fully informed about the aims of the survey. Any respondents who did not agree to take part in the survey were removed from the analysis.

\section{Findings}


The findings are presented in two parts. First the results of the Delphi method are presented and then the results of the wider survey are presented. The results of both phases are then considered together in the discussion and conclusion of the paper.

\section{The Delphi method findings}

\section{$\underline{\text { Publishing decisions }}$}

In the first two rounds of the Delphi, the most important factors reported to affect publishing decisions were: 1) Journal linked to/ suitable for my research $(100 \%), 2)$ Review process (e.g. quality/ speed) (58\%), 3) Status of journal in field (e.g. age/ reputation) (50\%). Most panelists (75\%) agreed with these factors. However, some stated that JIF alone is considered when deciding where to publish. Most Delphi panelists do not pay to publish (e.g. open access) (67\%). Reasons for this, explored in round 3, included not wanting to pay as 'we already work as reviewers for free.'. However, there was a 'clear differentiation between paying to be published in "predator journals" and publishing open access', especially as 'all the best ranked journals in Communication are entering the open access by authors payment system'.

Another factor that was highlighted in the early rounds of the Delphi was the dilemma of wanting to increase exposure in the public relations community whilst also supporting the field by publishing in its journals. Panelists stated that they had to balance this against a) the lack of status and recognition that public relations journals have due to their relative recency, $b$ ) methodological issues in some public relations journals, and c) the need to publish in high ranked journals for career progression. When asked to reflect on this in round 3, panelists expanded, highlighting that some public relations journals have a 'quantitative and often functionalist orientation' which reduces the likelihood of using them as a publication outlet for qualitative work. Others argued that publishing in public relations journals is essential to 
highlight the importance of the field to academia and to show ' my institution that this field has relevance'.

Despite most panelists (86\%) not having English as a first language, in the early rounds of the Delphi, there was a clear division of opinion over whether language is important in deciding where to publish. In round 3 we sought to explore whether this is an issue that primarily affects non-English speakers. Almost $3 / 4$ of panelists (71\%) agreed that language is considered with a focus on publishing in English, as it is 'internationally received', 'is the lingua franca of science' and that 'my university wants us to publish in English'. However, it was also stated that if the paper being published is context bound, then it would be published in the native language, as studies 'from my country are often seen as not relevant / important / applicable for other markets'.

\section{$\underline{\text { Journal outlets }}$}

In rounds 1 and 2 of the Delphi discussion, panelists were asked to rank journals in order of perceived impact/ importance. The top five journals were: 1) Public Relations Review (receiving $66 \%$ of votes for $1^{\text {st }}$ ranking), 2) Journal of Communication Management (33\%), 3) Corporate Communications (25\%) and European Journal of Communication Research (25\%), 5) International Journal of Strategic Communication (33\%) (see Figure 1). In round 3, whilst a third of panelists agreed with the ranking, there was continued disagreement, with $50 \%$ of the panelists neither agreeing nor disagreeing. Comments from the panelists provided some insights on the continued disagreement. The prominence of English language journals was highlighted, with one panelist stating that the list 'doesn't reflect the European reality'. Another panelist stated that they agreed with the ranking list, but 'not in terms of quality of the journals, but in terms of impact', supporting this, another panelist highlighted that 'PRR is SSCI listed 
with the highest IF of those in the list, therefore it needs to be Nol, not because it is of higher quality.

\section{**[INSERT FIGURE 1] **}

In rounds 1 and 2 of the Delphi, 8 public relations and communication journal titles were mentioned by at least 1 respondent, but these titles were not ranked highly by all. The top 5 reasons provided for this were as follows: 1) Not applicable/ Not heard of the journal before $(53 \%)$; 2) Not specific to public relations $(27 \%)$; 3) Journal publishes in another language $(22 \%)$; 4) Low JIF (11\%); and 5) Issues with the review process (5\%). Half of panelists stated that the reasons given 'definitely reflect' their perception of why journals are not ranked highly. However, a third neither agreed, nor disagreed, and 2 panelists completely disagreed. Panelists stated that whilst most of the factors can explain low rankings, language is overlooked: 'There are huge communities in French and Spanish languages, for example, with international titles, but not in English', and as a result, publishing in another language (other than English) is not a reason that they consider should affect journal ranks. Some panelists in the Delphi phase indicated that language is overlooked in publishing and the development of journal ranks. Most panelists stated that they agreed or strongly agreed (58.3\%) that there are enough journals in the field, highlighting that it is important to consolidate the body of knowledge and therefore suggesting no more are needed, but suggested that 'being supportive of non-English high ranked publications could establish a larger "PR" community'.

Most panelists publish outside of the field of and communication management. We asked panelists about their experiences and perceptions of doing so. The most important reasons for identified in rounds 1 and 2 included: 1) personal and academic goals (92\%); 2) to link research with other fields $(75 \%) ; 3)$ because of ranking problems with public relations journals $(67 \%)$, and 4) because of ranking opportunities outside of public relations $(67 \%)$. In round 3 most 
respondents agreed with the order of the reasons provided, but some suggested that ranking is the most important factor. Additional reflections suggested that there may be additional factors such as wanting to be "be a "public intellectual"'. In the wider survey, many respondents reported that they also publish outside of the field. Despite frequently publishing outside of the field of public relations and communication management, some barriers were highlighted by Delphi panelists. The most important barriers were: 1) topic barriers (75\%); 2) previous rejections or expectations of rejection (50\%); and 3) methodological barriers $(33 \%)$. When explored again in round 3, most panelists agreed, suggesting a certain degree of consensus had been reached. In the wider survey, although many respondents did not report to have experienced any challenges, some respondents mentioned issues $(n=15,50 \%)$ such as difficulties with language or differences in perspective or methodological approach.

\section{$\underline{\text { Institutional expectations and evaluations }}$}

In the early rounds of the Delphi research, most panelists (75\%) reported that journal articles were the main unit of assessment in their institution/country. Other factors included book chapters, grant applications, and influence or prestige factors, such as international research projects. In round 3, all panelists agreed with journal articles being the main unit of assessment. In a later question it was highlighted that 'quantity above quality is what matters at university level'. Most panelists stated that they are expected to publish in high ranking journals and that careers depended upon this, with publication quality assessed by journal indexes or national ranking systems. Pressure to publish appears to vary between institutions, with eight Delphi panelists stating they are under pressure, and four stating they are not. To explore this further, in round 3 we asked panelists for their reflections. Some stated that variations could be explained by the 'country assessment model and scientific language policies'. Others highlighted variations may exist between academics at different career stages, stating that 'ones 
[academics] not under pressure are probably older colleagues. The younger ones, who are still on the market, are definitely under pressure'.

\section{The wider survey}

\section{$\underline{\text { Publishing decisions }}$}

In the wider survey, JIF was also an important factor reported by most respondents $(\mathrm{n}=21$, $70 \%)$. Other factors identified in the wider survey included special issue calls $(\mathrm{n}=11,37 \%)$ and previous experience $(\mathrm{n}=15,50 \%)$. The methodology of outputs (i.e. qualitative or quantitative focus) was not an important influence in the choice of publication outlet $(n=20,66 \%)$. Like the Delphi panelists, over half of the respondents $(\mathrm{n}=18,60 \%)$ to the wider survey also prioritize publishing in public relations or strategic communication journals. Reasons for this included the notion that these journals are 'read by our peers' and that 'some discussions are better had with people attuned to specific topics'.

\section{$\underline{\text { Journal outlets }}$}

When respondents to the wider survey were asked about how likely they would be to publish in most popular public relations and strategic relations journals (as determined from the Delphi phase), respondents also indicated a preference for Public Relations Review (see Figure 2), which supports it being the preferred outlet for the field.

\section{**[INSERT FIGURE 2 HERE]**}

\section{$\underline{\text { Institutional expectations and evaluations }}$}

In the wider survey many respondents reported that evaluations of outputs can impact funding opportunities and/or career progression. When asked about feeling under pressure, some 
respondents appeared indifferent and stated that 'publishing is part of the job', and 'simply what you are paid to do', however, most respondents $(\mathrm{n}=19,63 \%)$ reported that they felt under pressure to publish. Such pressure was reported by scholars across the career spectrum.

\section{Language challenges}

Most respondents who completed the wider survey did not have English as a first language $(\mathrm{n}=27,90 \%)$. Despite this, and the prominence of English language journals in the field, most respondents reported that their institution did not offer any services to help with publishing in English. Instead, many reported using proofreading or editing services ahead of publication. Most respondents also publish in non-English journals. Whilst some said that their institution is supportive of this, for instance stating that academics have 'total freedom concerning where to publish, the institution is rewarded for publishing in top journals, international or national ones' other respondents were unsure, and others stated that their institutions were not supportive since they prefer 'internationalization, not national language publication'.

\section{Conclusion-Discussion and directions for future research}

Having established that the field of public relations and communications management lacks an accepted list of high quality or impactful journals, this study aimed to explore how public relations and communications management academics across different career stages in Europe decide where to publish their research. We were also interested in the extent to which pressures to 'perform' influence their priorities. and what factors affect the decisions made, considering how academic excellence is perceived a 'performance'.

Findings indicate that most academics feel under pressure to publish, either through formal systems or because 'it's what you're paid to do'. This echøes observations from the literature that academics must 'perform' according to set indices to succeed. For instance, Oravec (2017) 
explains that academics are "gaming the system" (p-424) to achieve higher impact. The groups expressing most pressure were ECRs and senior academics, suggesting pressure at both ends of career trajectory. This anxiety largely relates to the relation between publications, career progression and funding opportunities. These results may reflect job anxiety among aspiring entrants to academia and status anxiety for their professors. Tung and McKercher's (2017) study in tourism suggests that, whereas those who are now senior academics may have needed no teaching or field qualifications at the start of careers, current entrants must have both practice and academic credentials. It seems reasonable to extrapolate from the tourism research and conclude that younger researchers are under more pressure than their predecessors because of changing appraisal systems and a shrinking employment market. Such pressures are linked in the literature to the marketisation of higher education and the requirements to reflect the competitive advantage of the institution through high-ranking publication, even if the intrinsic value is low (Oravec, 2017).

Despite wanting to publish in the field of public relations and communication management, most respondents to the wider survey expressed the view that their publishing opportunities were limited by the small range of high impact publications. The Delphi panel felt that the low rankings of public relations journals, together with problems of field definition, hold back the development of the field. There were some calls for greater interdisciplinary research, and awareness that the dominant methodological approach of journals influenced decisions regarding where to publish. While the Delphi panel mostly submitted to journals that offered a suitable fit for their research, the survey respondents mentioned JIF and previous experience with the journal above other factors. The importance of prior experience can also harm journal choice, with several criticisms of the processes of journals submission, review and acceptance, including multiple mentions of delay in reviews. The Delphi panel offered detail examples of 
poor reviewing processes, long delays, contradictory reviews with no editorial guidance and other poor experiences. It is hoped that the annotated list of preferred publications (Table 1) will assist academics in their choices. Suggestions for future research (below) include possibilities for mentorship across career points.

**[TABLE 1 HERE]**

Further challenges related to language. Most of the respondents to the wider survey did not have English as a first language. However, the only journals with any ranking are English. While many respondents mentioned their national publications as a preferred outlet on both language and cultural grounds, they faced pressure to publish in English. Despite this, institutions did not appear to offer support such as translation, editing or proof-reading services. The dominance of English in academic publishing is not exclusive to public relations, but it does lead to unfair pressure on non-native speakers, as reported in responses, and therefore greater difficulties in performing. This finding reflects observations in the literature (Lawrence, 2007; Wouters et al, 2015) that performance metrics distort the practice of academics, in this instance requiring them to write in non-native languages to achieve recognition.

\section{Limitations}

Although the wider survey enabled insights to be gathered from academics across the career spectrum, the survey was completed by a small sample of academics. This was likely due to the COVID-19 pandemic and the resultant pressures that academics were facing at the time. The small sample may limit the generalisability of the results gathered, especially as many of the respondents were from one country (Spain). Nevertheless, similar concerns emerged from both methods of data gathering, suggesting a clear agenda for discussion and further research. Moreover, despite these limitations, an annotated journal list for the field of public relations 
and communications management was produced (see Table 1) and this could be used by academics to identify appropriate outlets for their research and could be used by institutions and funders in the evaluation of publications by academics in the field.

\section{Future research}

The authors consider this study to be an initial enquiry into the hitherto underexplored debate concerning publishing choices in public relations and communications management scholarship. Several questions arise from this preliminary research:

1. Should universities and university colleges develop resources and/or mentorship programmes to support scholars manage their publishing decisions?

2. How can journal editors in the public relations field improve submission and review processes, including offering clearer advice to authors.

3. Should public relations academics publish outside the field to advance their careers and enhance their employers' reputations or publish in the lower ranking 'home' journals? What are the implications of such choices for the field?

4. How do non-native English speakers succeed in publishing when high ranking journals are primarily in English? What assistance can be offered, by institutions or publications?

This study raises a range of issues facing academics in public relations and communication management when considering where to publish their research. The authors indicate some directions for further research and invite the community to reflect on these initial findings and consider how publication challenges could be reduced. 


\section{References}

Adler, R., Ewing, J. and Taylor, P. (2009), "Citation Statistics: A Report from the International Mathematical Union (IMU) in Cooperation with the International Council of Industrial and Applied Mathematics (ICIAM) and the Institute of Mathematical Statistics (IMS)", Statistical Science, Vol. 24 No. 1, pp. 1-14.

Albu, O. B. and Flyverbom, M. (2019), “Organizational Transparency: Conceptualizations, Conditions, and Consequences”, Business \& Society, Vol. 58 No. 2, pp. 268-297.

Bence, V. and Oppenheim, C. (2005) "The Evolution of the UK's Research Assessment Exercise: Publications, Performance and Perceptions”. Journal of Educational Administration and History, Vol. 37 No. 2, pp. 137-155. doi: 10.1080/00220620500211189

Bozeman, B. and Sarewitz, D. (2011) "Public Value Mapping and Science Policy Evaluation”, Minerva, Vol. 49 No. 1, pp. 1-23.

Burke, J. Bergman, J. and Asimov, I. (1983) The impact of science on society. Washington, DC: National Aeronautics and Space Administration.

Butler, J. (1990) Gender trouble: Feminism and the subversion of identity. Routledge: New York, USA. 
CareersAdvice (2011) 'The REF and Its Consequences for Academic Jobseekers', available at: http://www.jobs.ac.uk/careers-advice/working-in-higher-education/1668/the-refand-its-consequences-for-academic-jobseekers> (accessed 14 July 2019).

Cosic, R., Shanks, G. and Maynard, S. B. (2015) “A business analytics capability framework", Australasian Journal of Information Systems. Australia, Vol.190. doi: 10.3127/ajis.v19i0.1150.

Cronin, A. M. (2016) "Reputational capital in "the PR University": public relations and market rationalities", Journal of Cultural Economy, Vol. 9 No. 4, pp. 396-409.

DORA (2019) 'Improving how research is assessed', available at: https://sfdora.org/ (accessed 29 June 2020).

Edwards, L. (2012) 'Defining the 'object' of public relations research: A new starting point", Public Relations Inquiry. Vol. 1 No. 1, pp. 7-30.

Edwards, L. (2018) Understanding Public Relations: Theory, Culture and Society, Sage: Thousand Oaks, CA.

Elsevier (2020) Industrial Marketing Management, available at: https://www.journals.elsevier.com/industrial-marketing-management (accessed 24/07/2020).

Eyun-Jung, K., Pasadeos, T. and Ertem-Eray, T. (2019) "Growth of public relations research networks: a bibliometric analysis”, Journal of Public Relations Research, Vol. 31 No. 1-2, pp. 5-31, doi:10.1080/1062726X.2019.1577739.

Fawkes, J. (2018) “The evolution of public relations research - an overview”, Communication \& Society, Vol. 31 No. 4, pp.159-171. doi: 10.15581/003.31.4.159.

Ferguson, M. A. (1984) 'Building theory in public relations: Interorganizational relationships', paper presented at the Association for Education in Journalism and Mass Communication Annual Convention, Gainesville, FL.

Gregory, A. and Fawkes, J. (2019) “A global capability framework: Reframing public relations for a changing world", Public Relations Review, Vol. 45 No. 3 , doi.org/10.1016/j.pubrev.2019.05.002.

Hansen, H. K., Christensen, L. T. and Flyverbom, M. (2015) "Introduction: Logics of transparency in late modernity: paradoxes, mediation and governance", European Journal of Social Theory, Vol.18, No. 2, pp.117-131.

Holbrook, J. B. and Frodeman, R. (2010) Comparative Assessment of Peer Review (CAPR), paper resented at EU/US workshop on peer review: Assessing 'broader impact' in research grant applications Brussels, Belgium. Available at: https://digital.library.unt.edu/ark:/67531/metadc86179/ (accessed 14 July 2020). 
Honig, B., Lampel, J., and Drori, I. (2014) Handbook of Organizational and Entrepreneurial Ingenuity, Edward Elgar Publishing: Cheltenham, UK.

Lawrence, P. (2007) “The Mismeasurement of Science”, Current Biology. Vol 17 No. 15.

L'Etang, J. (2004) Public Relations in Britain: A History of Professional Practice in the Twentieth Century, Lawrence Erlbaum Associates: New Jersey, USA.

Molony, K. and McGrath, C. (2020) Rethinking Public Relations: Persuasion, Democracy and Society, Routledge: UK.

Morehouse, J. and Saffer, A. (2018) "A bibliometric analysis of dialogue and digital dialogic research: mapping the knowledge construction and invisible colleges in public relations research", Journal of Public Relations Research. Vol. 30 No. 3 pp. 65-82.

Mutum, D. (2019) Updated Australian Business Deans Council (ABDC) Marketing Journals List 2016, available at: https://www.dilipmutum.com/2016/09/australian-businessdeans-council-abdc.html (accessed 14 July 2020).

Oravec, J. A. (2017) "The manipulation of scholarly rating and measurement systems: constructing excellence in an era of academic stardom", Teaching in Higher Education. Vol. 22 No. 4 pp. 1-14.

PLoS Medical Editors (2006) “The Impact Factor Game”, PloS Medicine, Vol. 3 No. 6, e291.

PRCA (2019) PR and Communications Census 2019, available at: https://www.prca.org.uk/sites/default/files/PRCA_PR_Census_2019_v9-8pdf\%20\%285\%29.pdf (accessed: 29 June 2020).

Rossner, M., Van Epps, H. and Hill, E. (2007) "Show Me the Data", The Journal of Cell Biology, Vol. 179 No. 6, pp. 1091-1092.

REF (2020) Research Excellence Framework, REF, available at: https://ref.ac.uk/ (accessed 24 July 2020).

Sallot, L. M., Lyon, L. J., Acosta-Alzuru, C., and Jones, K. O. (2003) "From aardvark to zebra: A new millennium analysis of theory development in public relations academic journals", Journal of Public Relations Research, Vol. 15 No. 1, pp. 27-90. doi:10.1207/S1532754XJPRR1501_2.

Salter, A., Molas-Gallart, J. and Duran, X. (2002) Measuring Third Stream Activities Science and Technology Policy Research: Russel Group Universities, available at: https://www.academia.edu/532097/Measuring_third_stream_activities> (accessed 14 July 2020).

Seglen, P. O. (1997) "Why the Impact Factor of Journals Should Not Be Used for Evaluating Research”, BMJ : British Medical Journal, Vol. 314 No. 7079, pp. 498-502. 
Sourani, A. and Sohail, M. (2015) The Delphi Method: review and use in construction management research. Loughborough University. Journal contribution. https://hdl.handle.net/2134/16465.

Tench, R. and Yeomans, L. (2013) Exploring Public Relations. $3^{\text {rd }}$ ed. Pearson Education Limited: London.

Trujillo, N. and Toth, E. L. (1987) "Organizational Perspectives for Public Relations Research and Practice”, Management Communication Quarterly. Vol. 1 No. 2, pp. 199-231.

Tung, V. and McKercher, B. (2017) "Negotiating the rapidly changing research, publishing, and career landscape", Tourism Management, Vol. 60, pp. 322-331.

Vanclay, J. K. (2012) "Impact Factor: Outdated Artefact or Stepping-Stone to Journal Certification?" Scientometrics, Vol. 92 No. 2, pp. 211-238.

Velten, H. R. (2012) 'Performativity and Performance'. Neumann, B. and Nünning, A. (Ed.s), Travelling Concepts for the Study of Culture: Concepts for the Study of Culture, De Gruyter: Berlin/New York, pp. 249-266.

Verčič, A., Verčič, D., and Sriramesh, K. (2012). "Internal communication: Definition, parameters, and the future", Public Relations Review. Vol. 38 pp. 223-230.

Wakefield, T. and Watson, R. (2014) "Delphi 2.0: A reappraisal of Delphi method for public relations research”, Public Relations Review. Vol 40 No 3, pp. 577-584. doi:10.1016/j.pubrev.2013.12.004.

Watson, T. (2008) "Public relations research priorities: A Delphi study", Journal of Communication Management, Vol. 12 No. 2, pp. 104-123.

Watson, T. (2015) What in the World is Public Relations? In: T. Watson, ed., Perspectives on Public Relations Historiography and Historical Theorization, Basingstoke: Palgrave Macmillan, pp. 4-19.

Wernick, A. (1991). Theory, culture \& society. Promotional culture: Advertising, ideology and symbolic expression, Sage Publications, Inc: UK.

Wouters, P., Thelwall, M., Kousha, K., Waltman, L., Rijcke, S. de, Rushforth, A. and Franssen, T. (2015) 'The Metric Tide Literature Review Supplementary Report I to the Independent Review of the Role of Metrics in Research Assessment and Management. 1. HEFCE, July 2015. 


\section{Figure 1.}

Journals titles ranked in order of perceived impact/ quality ( $1=$ highest perceived impact, $5=$ lowest perceived impact $)$ Data collected in Delphi, round 2

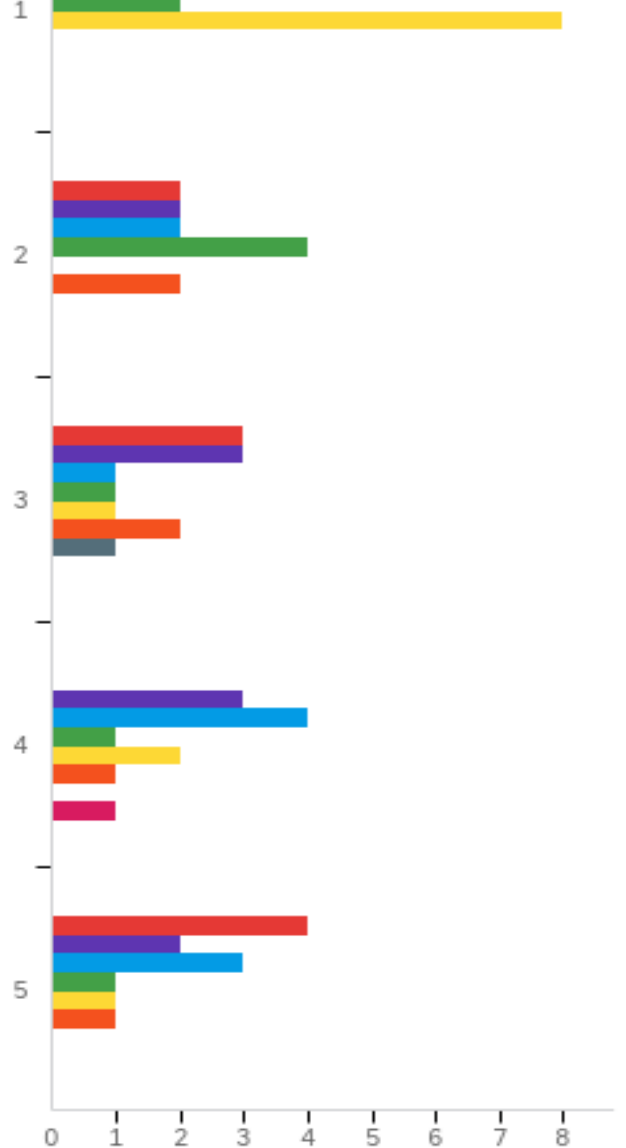

European Journal of Communication Research

Corporate Communications

International Journal of Strategic Communication

- Journal of Communication Management

Public Relations Review

Other, please state

Other, please state

Other, please state 
Figure 2.

Journal titles ranked in order of choice as an outlet for publication $(1=$ very likely, $5=$ very unlikely) Data collected in the wider survey

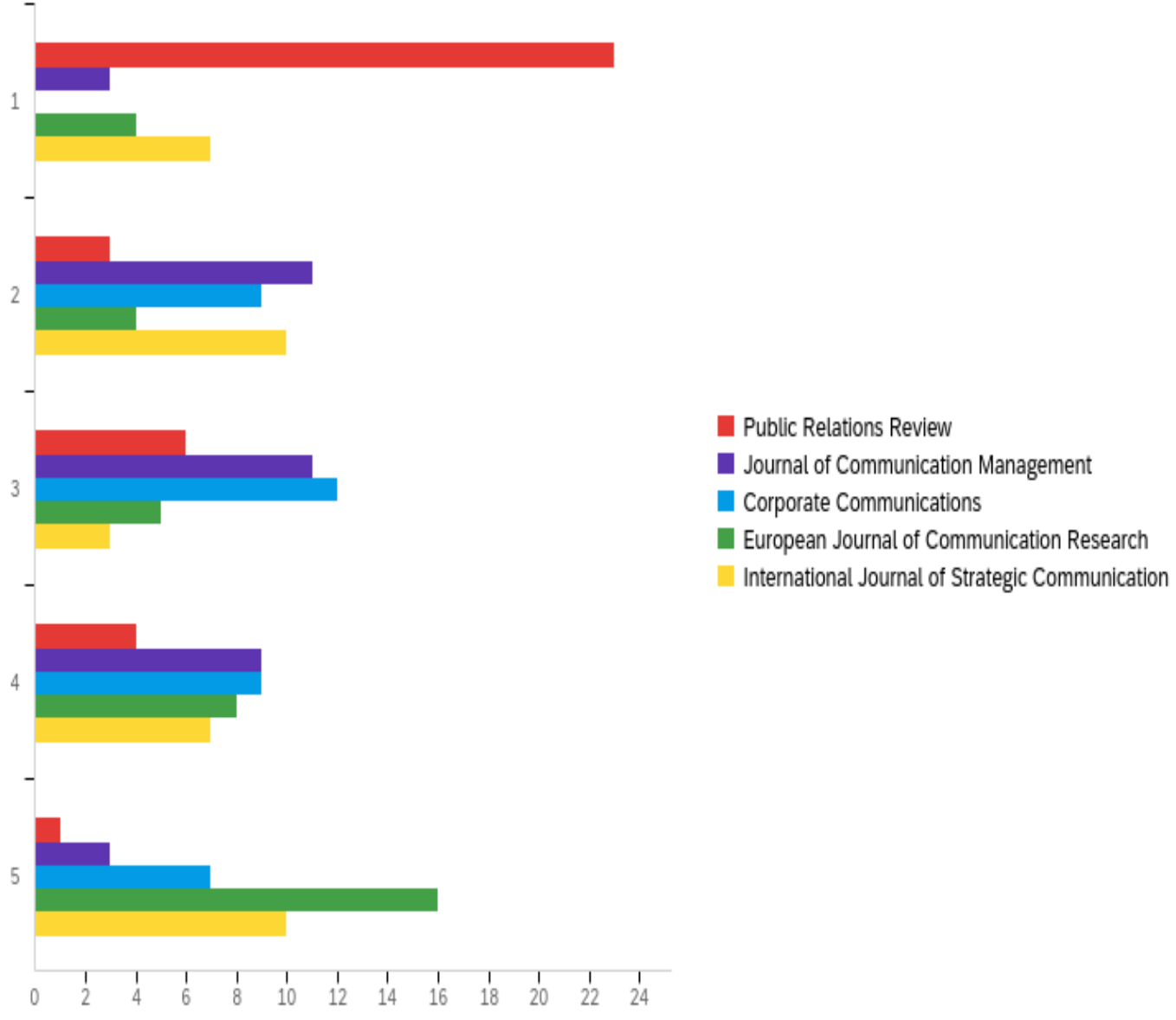

